\title{
To compare efficacy of Diclofenac by intramuscular route and rectal route in post surgical pain.
}

1. MBBS, FCPS (Gyne Obst) Assistant Professor Gynae Ameer ud Din Medical College, Lahore General Hospital, Lahore.

2. FCPS (Obs Gyne)

Associate Professor Gynae Ameer ud Din Medical College, Lahore General Hospital, Lahore.

3. FCPS (Medicine), MRCP (UK), FRCP (Edin), FRCP (Glasg), FRCP (London), MCPS-HPE Associate Professor Medicine AMC/PGMI/LGH, Lahore.

4. FCPS (Anesthesia) Senior Registrar Medicine Lahore General Hospital, Lahore. 5. MBBS

Senior Registrar Medicine Lahore General Hospital, Lahore.

Correspondence Address: Muhammad Imran Hasan Khan Department of Medicine AMC/PGMI/LGH, Lahore. mimranhkhan@hotmail.com

Article received on:

04/08/2020

Accepted for publication: $12 / 02 / 2021$

\section{INTRODUCTION}

Post-operative pain is predictable after any major surgery due to surgical trauma and manipulation of tissues. ${ }^{1}$

Pain management has a vital role in countless surgical techniques. In case of Cesarean delivery, it has more implication due to several psychological and social factors like initiation of breast feeding for optimizing bonding between mother and the baby. A number of studies have recorded the incidence of reasonable to severe post-operative pain counting almost over $80 \%$. $^{2,3}$ The longer duration of persistence of such pain is not only consistent with other post-operative complications but also with stress reactions resulting in lengthening in post-operative restoration time and delays in hospital discharges and resumption of daily routine activities. Such clinical and psychological effects (short term and long term) increase morbidity and mortality with negative impact on quality of life. Negative clinical outcomes in response to ineffective postoperative pain controls include discomfort, hemodynamic compromise, pneumonia, deep vein thrombosis, pulmonary embolism, myocardial infarction, delayed wound healing, disturbed sleep and depression. ${ }^{4}$ Pain management plays a necessary role in reducing mortality and morbidity owing to postoperative complications. ${ }^{5}$ Uncontrolled pain leads to increased hospital stay and hence increased use of hospital resources.

Effective pain management has an important role to play in low segment cesarean sections as it helps in early communication of mother with the newborn and initiation of infant feeding. ${ }^{6,7}$ Opioid analgesics for post-op pain relief are gaining numbers, but on the other hand it ends up with dangerous after effects like CNS depression and altered Gl motility. ${ }^{8}$ Recently physicians have focused on Non-steroidal anti-inflammatory 
drugs (NSAID) for pain relief because of various anticipated problems associated with opioids. ${ }^{9,10}$

Diclofenac is amongst the NSAIDs class of medicine having an effective post-operative pain relief resulting in lowering postoperative narcotic demands. ${ }^{11-15}$ The consequences of previous studies are variable pertaining to the post cesarean pain reduction via use of diclofenac either by intramuscular route or in suppository form. A study of sixty patients receiving analgesics who underwent low segment cesarean section, had been divided into three groups; one who used paracetamol alone, second; who used diclofenac only, and the third group used their combination. These were investigated and the outcomes confirmed that patients who were given a combination of diclofenac and paracetamol needed less opioids than those who were given paracetamol alone. ${ }^{16}$

In another study of parturients requiring elective cesarean delivery under spinal anesthesia, postoperative analgesic effects of diclofenac and/or paracetamol were evaluated. Diclofenac given after cesarean delivery had effective pain relief with significantly higher morphine-sparing effects. ${ }^{17}$

Effective pain relief is significant in mothers who underwent cesarean delivery to enhance the power of self-care, ensuing early discharge and resuming routine activities. We conducted this study in Lahore General Hospital, Lahore to address the disparities regarding efficaciousness of painkiller and diclofenac especially by different routes of administration.

\section{MATERIAL \& METHODS}

It was a randomized, double-blind trial of 100 patients who were brought to the tertiary care hospital for cesarean delivery irrespective of any indication.

Following patients were included in the study:

1. Age between $17-40$ years.

2. ASA I and II class of American Society of Anesthesiologists Physical Status Classification.

\section{Term pregnancy.}

Following patients were excluded from the study:

1. Having an allergic history to Paracetamol and NSAIDS (Diclofenac)

2. ASA III-VI class of American Society of Anesthesiologists Physical Status Classification.

3. General Anesthesia.

The study was conducted at Lahore General Hospital after obtaining permission from the hospital ethical committee (PGMI/LGH/AMC; ARTICLE/RESEARCH No. 17-23). After obtaining informed written consent from the patient and getting included in the study, the patients underwent Cesarean section under subarachnoid block. The regional anesthesia was given by using a 27G spinal needle and with identical approach (in sitting position at L2-3, L3-L4 or L4-L5 space) and drugs, Marcaine (Bupivacaine SP percentage $0.5 \%$ ). The vital signs were continuously monitored during whole surgery and in the post-anesthesia care unit. Meanwhile, in post-anesthesia care, post-operative pain in all patients was evaluated by using Visual Analogue Score (VAS) 17. For all patients with significant pain, medicine was given for pain relief. Patients were randomly divided into 2 groups. One group received the diclofenac sodium in intramuscular form and the other group in suppository form. If the pain was not relieved with diclofenac by either route, rescue medications were given (opioids, paracetamol etc). The Intensity and length of pain was evaluated with the aid of Visual Analogue Score (VAS) score at 0 hrs, 2 hrs, 4 hrs, $6 \mathrm{hrs}, 12 \mathrm{hrs}$ and 24hrs postoperatively. The data was analyzed using SPSS version 23 and was reproduced in the form of mean and percentages. Chi-square was applied to calculate the P-value.

\section{RESULTS}

The necessary demographic characteristics were found similar in both the groups. The necessary medical and obstetric parameters are shown in Table-I \& II. 


\begin{tabular}{|l|c|c|c|c|}
\hline \multicolumn{1}{|c|}{ Parameters } & Rectal Route & Intramuscular Route & Statistical Test & P-Value \\
\hline Maternal weight (Kg) & $74.63 \pm 9.07$ & $76.76 \pm 8.12$ & -1.232 & 0.221 \\
\hline Gestational age at delivery (wks) & $38.42 \pm 1.34$ & $37.90 \pm 1.50$ & -1.826 & 0.071 \\
\hline \multicolumn{1}{|c|}{$\mathbf{N}(\%)$} & $\mathbf{N}(\%)$ & Fisher's Exact Test & & 0.640 \\
\hline Booked & $42(84.0)$ & $44(88.0)$ & 0.219 & \\
\hline Unbooked & $8(16.0)$ & $6(12.0)$ & & 0.603 \\
\hline $\begin{array}{l}\text { Primigravida } \\
\text { Multigravida }\end{array}$ & $11(22.0)$ & $13(26.0)$ & 0.271 & \\
\hline
\end{tabular}

\begin{tabular}{|c|c|c|c|c|}
\hline & Rectal n (\%) & Intramuscular $\mathbf{n}(\%)$ & Statistical Test & P-Value \\
\hline $\begin{array}{l}\text { No of patients who were administered } \\
\text { rescue analgesia }\end{array}$ & $13(43.86 \%)$ & $18(58.14 \%)$ & $x 2=1.57$ & 0.21 \\
\hline $\begin{array}{l}\text { Total number of doses of rescue } \\
\text { analgesic agent administered }\end{array}$ & $18(42.03 \%)$ & $22(57.97 \%)$ & & \\
\hline Mean \pm SD & $1.44 \pm 0.52$ & $1.42 \pm 0.63$ & $t=2.35$ & 0.027 \\
\hline Median & 1 & 1 & & \\
\hline Range & 1 & 2 & & \\
\hline \multicolumn{5}{|c|}{ Time interval between post-operative analgesia and rescue analgesia (hrs) } \\
\hline Mean \pm SD & $4.39 \pm 2.78$ & $3.92 \pm 2.52$ & $t=-0.29$ & 0.77 \\
\hline Median & 4.0 & 3.5 & & \\
\hline Range & 9.67 & 10.25 & & \\
\hline \multicolumn{5}{|l|}{ Relief of pain } \\
\hline Yes & $30(84.8)$ & $28(78.8)$ & $X 2=0.257$ & 0.612 \\
\hline No & $3(15.2)$ & $5(21.2)$ & & \\
\hline
\end{tabular}

\begin{tabular}{|c|c|c|c|c|}
\hline & Rectal & Intramuscular & T-test & P-Value \\
\hline \multicolumn{5}{|c|}{6 hours post op } \\
\hline Mean \pm SD & $5.52 \pm 1.46$ & $5.58 \pm 1.82$ & 0.15 & 0.88 \\
\hline Median & 5 & 4 & & \\
\hline Range & 7 & 9 & & \\
\hline \multicolumn{5}{|c|}{12 hours post op } \\
\hline Mean \pm SD & $5.12 \pm 1.56$ & $5.52 \pm 1.39$ & 1.08 & 0.28 \\
\hline Median & 4 & 4 & & \\
\hline Range & 7 & 8 & & \\
\hline \multicolumn{5}{|c|}{18 hours post op } \\
\hline Mean \pm SD & $4.24 \pm 1.50$ & $4.79 \pm 1.29$ & 1.58 & 0.12 \\
\hline Median & 3 & 4 & & \\
\hline Range & 5 & 5 & & \\
\hline \multicolumn{5}{|c|}{24 hours post op } \\
\hline Mean \pm SD & $3.88 \pm 1.90$ & $4.76 \pm 1.75$ & 1.95 & 0.06 \\
\hline Median & 3 & 4 & & \\
\hline Range & 10 & 5 & & \\
\hline
\end{tabular}

Table-III. Pain score comparison. 


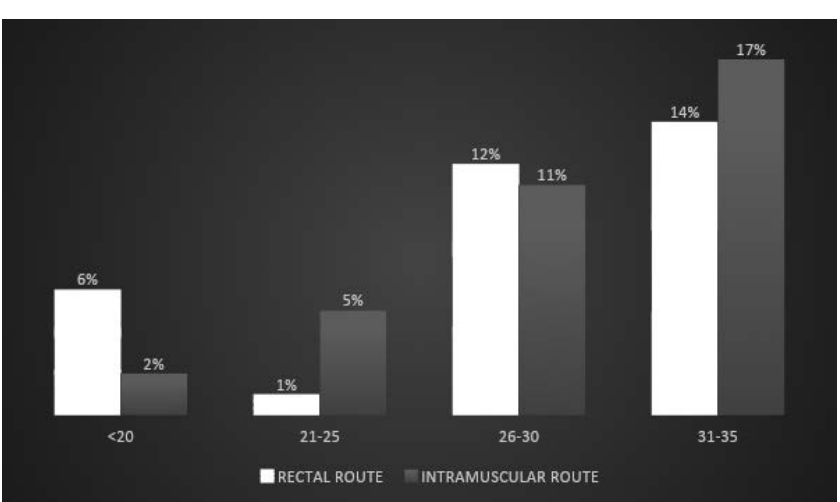

Figure-1. Age distribution.

\section{DISCUSSION}

Our results showed that highest demand for analgesia was in the 31-35 age group, in this age group $14 \%$ of the patients were given analgesia by the rectal route and $17 \%$ by the intramuscular route. In the age group of 26-30 years 12\% required analgesia by the rectal route and $11 \%$ by the intramuscular route and in the age group of patients less than 20 years the patients who were administered analgesia by the rectal route were $6 \%$ and $2 \%$ by the intramuscular route. The least requirement for analgesia was in the 21-25 age group where only $1 \%$ were administered analgesia by the rectal route and $5 \%$ by the intramuscular route. These results were contradictory to the guidelines published by the American college of surgeons according to which the requirements for analgesia decreases with the advancement in age ${ }^{18}$, this might be explained because of the fact that our study was conducted in a different population and small sample size might be another factor.

In our study, the mean maternal weight in kilograms of patients who were administered analgesia by the rectal route was $74.63 \pm 9.07$ and those who were administered analgesia by the intramuscular route was $76.76 \pm 8.12$, thus both the groups had almost equal distribution of weight which was helpful in comparing both the groups as stated by Sandra et al. according to which dose requirements increase in proportion to the increase in weight of patients..$^{19}$ We also compared the gestational age of patients of patients in weeks of those patients who required analgesia, the mean for those who were administered analgesia by the rectal route was $38.42 \pm 1.34$ an for those who were administered analgesia by the intramuscular route was $37.90 \pm 1.50$. Our results were similar to those reported by Adebayo et al. according to which gestational age was a strong mediator for analgesia requirements in post cesarean section patients. ${ }^{20}$ The percentage of booked patients who were given rectal analgesia were $84 \%$ and who were un booked were $16 \%$, those requiring intramuscular analgesia were $44 \%$ booked and $12 \%$ un booked, thus majority of population in our study who was administered analgesia either rectal or intramuscular being booked for cesarean section before delivery. Similar to our study Peter et al. devised a questionnaire to predict acute pain after cesarean section. ${ }^{21}$ We found that those patients who were given rectal analgesia $22 \%$ were primigravida and $78 \%$ were multigravida, those given by the intramuscular route were $26 \%$ primigravida and $74 \%$ were multigravida, thus multigravida patients were more responsive to both types of analgesia, consistent with our findings.

In our study, $43.86 \%$ of the patients in the rectal group required rescue analgesia as compared to the intramuscular group in which $58.14 \%$ of the patients required rescue analgesia and the mean for total number of doses for rescue analgesia in the rectal group was $1.44 \pm 0.52$ and the mean for total number of doses of rescue analgesia in the intramuscular group was $1.42 \pm 0.63$. Our results were somewhat similar to those of Lakshmi EY al. according to which analgesia by the rectal route improves quality and has longer duration. ${ }^{22}$ The mean for time interval between postoperative analgesia and rescue analgesia for those who were administered analgesia by the rectal route was $4.39 \pm 2.78$ hours as compared to the mean time for rescue analgesia by the intramuscular route, $3.92 \pm 2.52$ hours, these results show that rectal route increases the time duration of analgesia as compared to the intramuscular route. Our results were consistent with those of Heidari et al. according to which analgesia administered by the rectal route had better relief of pain as compared to the analgesia administered by the intramuscular route. ${ }^{24} \mathrm{We}$ 
found that $84.8 \%$ of the patients said that they had relief of pain after administration of analgesia by the rectal route and $78.8 \%$ of the patients had relief of pain after analgesia administration by the intramuscular route, again consistent with the findings of Heidari et al. ${ }^{23}$

The mean for the pain score after 6 hours post op by the rectal route was $5.52 \pm 1.46$ and by the intramuscular route was $5.58 \pm 1.82$, after 12 hours post op by the rectal route was $5.12 \pm$ 1.56 and by the intramuscular route was $5.52 \pm$ 1.39 , after 18 hours the mean for post op pain by the rectal route was $4.24 \pm 1.50$ and by the intramuscular route was $4.79 \pm 1.29$ and after 24 hours the mean for post op pain score by the rectal route was $3.88 \pm 1.90$ and by the intramuscular route was $4.76 \pm 1.75$. Our findings were consistent with those of McEwan et al. who reported that the codeine drug was absorbed rapidly by the rectal route but the plasma peak level was relatively lower and was achieved at the same time with both routes. ${ }^{24}$

Our study had a few limitations, firstly it was a single center study conducted in a similar type of ethnic population, we need a multi-center study with diverse ethnic populations to verify our results. Secondly, the sample size was small, we need a large sample size to verify our findings.

\section{CONCLUSION}

In a nutshell, the majority of patients who were given analgesia either by the rectal or intramuscular route were in the 31-35 age group, more rescue doses were required to control pain in case of analgesia by the intramuscular route and rectal route was more effective in controlling pain as compared to the intramuscular route of analgesia.

Copyright $(12$ Feb, 2021.

\section{REFERENCES}

1. Dahl JL, Gordon D, Ward S, Skemp M, Wochos S, Schurr $M$. Institutionalizing pain management: The postoperative pain management quality improvement project. J Pain. 2003; 4(7):361-71.
2. Apfelbaum JL, Chen C, Mehta SS, Gan TJ. Postoperative pain experience: results from a national survey suggest postoperative pain continues to be undermanaged. Anaesthesia \& Analgesia. 2003; 97(2):534-40.

3. Lee SY, Lee WH, Lee EH, Han KC, Ko YK. The effects of paracetamol, ketorolac, and paracetamol plus morphine on pain control after thyroidectomy. Korean J Pain. 2010; 23(2):124-30.

4. Neugebauer EA, Althaus A, Simanski C. Acute pain management. Rural Surgery: Springer; 2011. Pp. 6775.

5. Cattabriga I, Pacini D, Lamazza G, Talarico F, Di Bartolomeo R, Grillone G, et al. Intravenous paracetamol as adjunctive treatment for postoperative pain after cardiac surgery: $A$ double blind randomized controlled trial. Eur J Cardiothorac Surg. 2007; 32(3):527-31.

6. Akhavanakbari G, Entezariasl M, Isazadehfar $\mathrm{K}$, Kahnamoyiagdam $F$. The effects of indomethacin, diclofenac, and acetaminophen suppository on pain and opioids consumption after cesarean section. PICR. 2013; 4(2):136.

7. Pakartadbiri $S$, Rahimi E. Comparison of morphine and piroxicam in decreasing post cesarean pain. SJKUMS. 2001; 5(3):3-10.

8. Banik D, Hye MA, Akhtaruzzaman A, Aziz L, Yeasmeen S, Iqbal $\mathrm{K}$. Effect of small dose intermittent IV pethidine in combination with diclofenac for post-operative pain relief. Bangla JOL. 2014; 22(2):40-47.

9. Barkhori A, Drodian MR, Norozi M, Hashemi Shadmehri M, Shabani M. A comparative study of the effect of diclofenac, indomethacin, naproxen, and acetaminophen rectal suppositories on postcesarean pain. Journal of Birjand University of Medical Sciences. 2014; 20(4):338-45.

10. Irer B, Gulcu A, Aslan G, Goktay Y, Celebi I. Diclofenac suppository administration in conjunction with lidocaine gel during transrectal ultrasound-guided prostate biopsy: Prospective, randomized, placebocontrolled study. Urology. 2005; 66(4):799-802.

11. Ragavan N, Philip J, Balasubramanian S, Desouza $J$, Marr C, Javle P. A randomized, controlled trial comparing lidocaine periprostatic nerve block, diclofenac suppository and both for transrectal ultrasound guided biopsy of prostate. J Urol. 2005; 174(2):510-13. 
12. Haq A, Patel H, Habib M, Donaldson P, Parry J. Diclofenac suppository analgesia for trans rectal ultrasound guided biopsies of the prostate: A double-blind, randomized controlled trial. J Urol. 2004; $171(4): 1489-91$.

13. Dodd JM, Hedayati H, Pearce E, Hotham N, Crowther CA. Rectal analgesia for the relief of perineal pain after childbirth: A randomized controlled trial of diclofenac suppositories. BJOG. 2004; 111(10):105964.

14. Ng A, Parker J, Toogood L, Cotton B, Smith G. Does the opioid sparing effect of rectal diclofenac following total abdominal hysterectomy benefit the patient? $\mathrm{Br}$ J Anaesth. 2002; 88(5):714-16.

15. Munishankar B, Fettes P, Moore C, McLeod G. A doubleblind randomized controlled trial of paracetamol, diclofenac or the combination for pain relief after caesarean section. International Journal of Obstetric Anaesthesia. 2008; 17(1): 9-14.

16. Siddik SM, Aouad MT, Jalbout MI, Rizk LB, Kamar $\mathrm{GH}$, Baraka AS. Diclofenac and/or propacetamol for postoperative pain management after cesarean delivery in patients receiving patient controlled analgesia morphine. Regional Anaesthesia and Pain Medicine. 2001; 26(4):310-15.

17. Hawker GA, Mian S, Kendzerska T, French M. Measures of adult pain: Visual analog scale for pain (vas pain), numeric rating scale for pain (nrs pain), mcgill pain questionnaire (mpq), short-form mcgill pain questionnaire (sf-mpq), chronic pain grade scale (cpgs), short form-36 bodily pain scale (sf36 bps), and measure of intermittent and constant osteoarthritis pain (icoap). Arthritis Care Res. 2011; 63(S11):S240-52.
18. American College of Surgeons. "Post-surgery guideline could reduce opioid prescriptions by as much as 40 percent." Accessed July 16, 2020.

19. Kane-Gill, Sandra L., Nicholas P. Wytiaz, Lisa M. Thompson, Karina Muzykovsky, Mitchell S. Buckley, Henry Cohen, and Amy L. Seybert. "A real-world, multicenter assessment of drugs requiring weightbased calculations in overweight, adult critically III patients." The Scientific World Journal 2013 (November 30, 2013).

20. Akadri, Adebayo Adekunle, and Oluwaseyi Isaiah Odelola. "Labour pain perception: Experiences of Nigerian Mothers." The Pan African Medical Journal 30 (2018): 288.

21. Pan, Peter H., Ashley M. Tonidandel, Carol A. Aschenbrenner, Timothy T. Houle, Lynne C. Harris, and James $\mathrm{C}$. Eisenach. "Predicting acute pain after cesarean delivery using three simple questions." Anesthesiology 118, no. 5 (May 2013): 1170-79.

22. Mahajan, Lakshmi, Vaishali Mittal, Ruchi Gupta, Himani Chhabra, Jyoti Vidhan, and Ashreen Kaur. "Study to compare the effect of oral, rectal, and intravenous infusion of paracetamol for postoperative analgesia in women undergoing cesarean section under spinal anesthesia." Anesthesia, Essays and Researches 11, no. 3 (2017): 594-98.

23. Heidari, S. Morteza, S. Zahra Mirlohi, and S. Jalal Hashemi. "Comparison of the preventive analgesic effect of rectal ketamine and rectal acetaminophen after pediatric tonsillectomy." International Journal of Preventive Medicine 3, no. Suppl1 (March 2012): S15055.

24. McEwan, P.E. Sigston, K. A. Andrews, H. A. Hack, A.M.C. Jenkins, L. May, L. Llewelyn BA, A. Mackersie; A comparison of rectal and intramuscular codeine phosphate in children following neurosurgery; Article in Pediatric Anesthesia 10(2):189-93 - February 2000. 


\section{AUTHORSHIP AND CONTRIBUTION DECLARATION}

\begin{tabular}{|c|l|l|}
\hline Sr. \# & \multicolumn{1}{|c|}{ Author(s) Full Name } & \multicolumn{1}{|c|}{ Contribution to the paper } \\
\hline 1 & Maryam Zulfiqar & $\begin{array}{l}\text { Original idea, Review of } \\
\text { literature, Initial manuscript } \\
\text { writing, Final review. } \\
\text { Introduction, Material and } \\
\text { Methods writing, Discussion } \\
\text { Review, Results review, Final } \\
\text { manuscript approval. } \\
\text { Discussion review, Limitations, } \\
\text { Final approval. }\end{array}$ \\
\hdashline 5 & Maimoona Ashraf & $\begin{array}{l}\text { Statistical analysis, Final } \\
\text { approval of manuscript. } \\
\text { Statistical analysis, Final } \\
\text { approval of manuscript. }\end{array}$ \\
\hline
\end{tabular}

